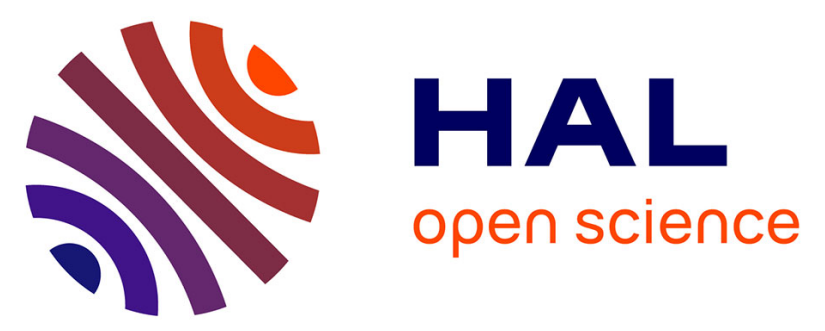

\title{
PKA-induced phosphorylation of ER $\alpha$ at serine 305 and high PAK1 levels is associated with sensitivity to tamoxifen in ER-positive breast cancer
}

\author{
Marleen Kok, Wilbert Zwart, Caroline Holm, Renske Fles, Michael
} Hauptmann, Laura J. Van'T Veer, Lodewyk F. A. Wessels, Jacques Neefjes, Olle Stål, Sabine C. Linn, et al.

\section{To cite this version:}

Marleen Kok, Wilbert Zwart, Caroline Holm, Renske Fles, Michael Hauptmann, et al.. PKA-induced phosphorylation of ER $\alpha$ at serine 305 and high PAK1 levels is associated with sensitivity to tamoxifen in ER-positive breast cancer. Breast Cancer Research and Treatment, 2010, 125 (1), pp.1-12. 10.1007/s10549-010-0798-y . hal-00554994

\section{HAL Id: hal-00554994 https://hal.science/hal-00554994}

Submitted on 12 Jan 2011

HAL is a multi-disciplinary open access archive for the deposit and dissemination of scientific research documents, whether they are published or not. The documents may come from teaching and research institutions in France or abroad, or from public or private research centers.
L'archive ouverte pluridisciplinaire HAL, est destinée au dépôt et à la diffusion de documents scientifiques de niveau recherche, publiés ou non, émanant des établissements d'enseignement et de recherche français ou étrangers, des laboratoires publics ou privés. 
PKA-induced phosphorylation of ERa at serine 305 and high PAK1 levels are associated with sensitivity to tamoxifen in ER positive breast cancer.

Marleen Kok ${ }^{1}$, Wilbert Zwart ${ }^{2}$, Caroline Holm³,4, Renske Fles ${ }^{1}$, Michael Hauptmann', Laura J. Van 't Veer', Lodewyk F.A. Wessels ${ }^{5}$, Jacques Neefjes $^{2}$, Olle Stål ${ }^{7}$, Sabine C. Linn ${ }^{8,9}$, Göran Landberg ${ }^{3,4}$ and Rob Michalides ${ }^{2}$ Departments of Experimental Therapy ${ }^{1}$, Cell Biology ${ }^{2}$, Bioinformatics and Statistics ${ }^{5}$ Pathology ${ }^{6}$, Molecular Biology ${ }^{8}$ and Medical Oncology ${ }^{9}$, Netherlands Cancer Institute, Amsterdam, the Netherlands, Center for Molecular Pathology ${ }^{3}$, Lund University, Malmö University Hospital, Malmö, Sweden, Breakthrough Breast Cancer Research Unit ${ }^{4}$, Paterson Institute for Cancer Research, Manchester, UK. Division of Oncology ${ }^{7}$, Department of Clinical and Experimental Medicine, Linköping University, Linköping, Sweden.

Running title Sensitivity to tamoxifen is influenced by PKA/ERoS305P and PAK1

Disclaimers None

Corresponding author Rob Michalides, Netherlands Cancer Institute Plesmanlaan 121, 1066 CX Amsterdam, The Netherlands

Phone 003120 5122022/Fax 003120 5122029/r.michalides@nki.nl 


\section{Purpose}

Phosphorylation of estrogen receptor $\alpha$ at serine 305 (ER $\alpha$ S305-P) by protein kinase $A(P K A)$ or p21-activated kinase 1 (PAK1) has experimentally been associated with tamoxifen sensitivity. Here, we investigated the clinical application of this knowledge to predict tamoxifen resistance in ER-positive breast cancer patients.

\section{Methods}

Using immunohistochemistry, a score including PAK1 and co-expression of PKA and ER $\alpha$ S305-P (PKA/ ER $\alpha$ S305-P) was developed on a training set consisting of 103 patients treated with tamoxifen for metastatic disease, and validated on 231 patients randomized between adjuvant tamoxifen or no treatment.

\section{Results}

In the training set, PAK1 levels were associated with tumor progression after tamoxifen ( $\mathrm{HR} 1.57,95 \% \mathrm{Cl} 0.99-2.48)$, as was co-expression of PKA and ER $\alpha$ S305-P (HR 2.00, 95\% CI 1.14-3.52). In the validation set, a significant tamoxifen benefit was found among the $73 \%$ patients negative for PAK1 and PKA/ER $\alpha$ S305-P (HR 0.54, 95\% Cl 0.34-0.87), while others (27\%) were likely to have no benefit from tamoxifen (HR $0.88,95 \% 0.42-1.82$ ). The test for interaction showed a significant difference in recurrence-free survival between groups defined by PAK1 and PKA/ER $\alpha$ S305-P ( $p=0.037)$. Elevated PAK1 and PKA/ ER $\alpha$ S305-P appeared to influence tamoxifen sensitivity.

\section{Conclusion}


Both PAK1 and PKA/ER $\alpha$ S305-P levels were associated with sensitivity to tamoxifen in breast tumors and the combination of these variables should be considered in predicting tamoxifen benefit.

Keywords PKA, PAK1, phosphorylation of ER, tamoxifen sensitivity, breast cancer

\section{INTRODUCTION}

Resistance to anti-estrogens is one of the major challenges in breast cancer treatment. For more than 25 years, the golden standard for endocrine treatment of breast cancer has been tamoxifen. However, approximately half 
of the patients with estrogen receptor alpha (ERd)-positive tumors do not respond to tamoxifen [1]. More recently, novel classes of endocrine agents have been introduced, including aromatase inhibitors and fulvestrant [2]. These drugs have a different mechanism of action as compared to tamoxifen $[3,4]$, and consequently, a different spectrum of patients responds to these novel agents [5-7]. To select an optimal adjuvant treatment [8], the identification of additional biomarkers is essential to select patients who will have no benefit from tamoxifen and should thereby be treated with alternative anti-estrogens.

Various mechanisms can contribute to tamoxifen resistance [9], including kinase activity that results in phosphorylation of ERa[10]. Phosphorylation of ERa at serine 305 (ERoS305-P) by protein kinase A (PKA) leads to an activation of ERaand to transcription of ERa-responsive genes in response to tamoxifen treatment $[11,12]$, thus inducing resistance. In addition, modification of ERa has been associated with p21-activated kinase 1 (PAK1) [13-15], and nuclear expression and amplification of the PAK1 gene correlates with tamoxifen resistance as well $[16,17]$.

Recently, we have presented the first clinical study showing that ER $\alpha$ S305-P may be a biomarker that, as suggested by the experimental studies, can identify patients unlikely to respond to tamoxifen [18]. In order to gain insights into the association between both PAK1 and active PKA with ERoS305-P and to determine their clinical relevance, we studied these three putative markers in a clinical setting $(n=334)$. We developed and validated a score integrating PKA activity, PAK1 and, ERoS305-P that is associated with benefit from 
tamoxifen benefit, enabling in more than $50 \%$ of the patients that will develop tamoxifen resistance.

MATERIALS AND METHODS

NKI-AVL, Lund and Linköping Universities ethical boards approved the studies. The data are presented according to the REMARK recommendations [19]. 


\section{Patients training series}

As previously described [18, 20], a consecutive series of breast cancer patients who had been treated at the Netherlands Cancer Institute-Antoni van Leeuwenhoekhuis hospital were selected according to the following criteria: 1) invasive $E R_{\alpha}$-positive breast carcinoma, 2) no adjuvant systemic treatment, 3) development of relapse before 2002, for which first-line tamoxifen monotherapy had been given. Tamoxifen was administered according to national guidelines of that time. Twenty nine patients were excluded due to insufficient tumor material. Analyses presented here are based on 103 patients. The clinico-pathological properties of the 103 patients were similar to those of the whole group of patients (data not shown).

\section{Patients validation series}

As described before, 564 premenopausal breast cancer patients were randomized to either 2 years of tamoxifen $(n=276)$ or no systemic treatment (control) $(n=288)[17,18,21,22]$. Here, we analyzed ER $\alpha$-positive tumors of 231 patients of this series for whom PAK1, pPKA and, ERoS305-P immunohistochemistry were available.

\section{Clinical endpoints}


In the training series, time to tumor progression (TTP) was considered the primary endpoint measured from the start of tamoxifen treatment until treatment was ended because of progression of disease. In the validation series, recurrence-free survival (RFS) was the primary endpoint measured from surgery to either local, regional, or distant recurrence or breast cancer specific death.

Immunohistochemistry (IHC)

Tissue microarrays (TMAs) were constructed using formalin-fixed paraffinembedded (FFPE) tumor blocks [23]. From both patient series, primary breast tumors were examined by immunohistochemistry.

Details regarding IHC are presented in the Supplementary Data (Table A1). ER $\alpha$ was considered positive when $>10 \%$ of invasive cells showed nuclear reactivity [22]. IHC and scoring with the monoclonal ERoS305-P antibody (Millipore \# 124-9-4) has been described previously [18]. PAK1 staining was performed and scored as described before and nuclear expression was assessed [17]. For antigen retrieval of phosphorylated PKA-catalytic subunit (threonine 197) (pPKA) (Cell Signaling, \#4781), citrate buffer (10 mM, pH 6.0) was pre-heated; slides were added for 15 minutes (microwave 300W), incubated overnight with the antibody (dilution 1:40) and detected using diaminobenzidine. pPKA cytoplasmatic intensity was evaluated. As this is the first report describing this antibody for $\mathrm{IHC}$, we used a simple cut-off comparing no pPKA with any pPKA expression. Scoring of the TMAs was performed without any information on disease outcome of the patients. To 
control phospho-specificity, a sample expressing pPKA was dephosphorylated with $1000 \mathrm{U}$ lambda phosphatase (2 hours, $37^{\circ}$ C)(Millipore). TMA images are available (http://telepathology.nki.nl login: ER305PAK1PKA, password:tamoxifen).

Cell culture, transfection, western blotting

MCF-7 cells were cultured in DMEM medium supplemented with $10 \%$ fetal calf serum and standard antibiotics. Two days before transfection, cells were kept in phenol red-free DMEM containing $5 \%$ charcoal-treated serum (Hyclone). 3x $10^{6}$ Cells were transfected [12] with expression constructs encoding PAK1 K423E [24], and/or the catalytic subunit of PKA [25] and after two days prepared for western blotting [18]. To activate PKA, forskolin (Sigma) was added $15 \mathrm{~min}$ prior to lysis at a concentration of $10^{-5} \mathrm{M}$. Antibodies against $\mathrm{ER}_{\alpha}$ (Stressgen Biotechnologies Corp), ER $\alpha$ S305P (Millipore), PAK1 (Cell Signaling, \#2602), PKA C- $\alpha$ (Cell Signaling, \#4782), and, $\alpha$-tubulin (Sigma) were used at the recommended concentrations.

Gene expression analysis

The gene expression dataset has been described previously and is part of the training series described in this paper [20]. Agilent 44K expression data are available at http://research.agendia.com. 
Analyses were performed using BRB Array Tools (version 3.6). First, using the gene set expression comparison tool, 302 pathways as defined by Biocarta were analyzed. The evaluation of pathways that are differentially expressed between ER305-P positive and ER305-P negative samples was done using a functional class scoring analysis as described by Xu et al. [26]. Fisher's Least Square (LS) summary statistic (10,000 permutations) was used to test which pathways were differentially expressed in ERoS305-P-positive tumors. First, a p-value is computed for each gene in a pathway. Then the set of $p$-values for a pathway is summarized by the LS summary statistics. For a set of $\mathrm{N}$ genes, the LS summary statistic $\left(\mathrm{LS}=\sum_{\mathrm{L}=1}{ }^{N}\left(-\log \left(\mathrm{p}_{\mathrm{i}}\right)\right) / \mathrm{N}\right)$ is defined as the mean negative natural logarithm of the $p$-values of the appropriate single gene univariate test [27].

Second, we related the pathways to either PKA or PAK1 using the Cancer Genome Anatomy Project (http://cgap.nci.nih.gov/Genes/GeneFinder) and 27 and 12 pathways out of the 302 were found to be related to PKA and PAK1, respectively. Next, we tested whether the list of significant pathways as defined by the LS statistic $(p<0.05)$ (see above) was enriched for PKA-related pathways using Fisher's Exact test [28].

\section{PAK1-PKA/ER $\alpha$ S305-P Predictive Score}

Tumors that express no PAK1 and show no co-expression of pPKA and ER $\alpha$ S305-P are classified as 'negative'. A negative PAK1-PKA/ ER $\alpha$ S305-P Score corresponds to a high likelihood of being tamoxifen sensitive. Tumors that express PAK1 or show co-expression of pPKA and $\mathrm{ER}_{\alpha} \mathrm{S} 305-\mathrm{P}$ are 
classified as 'positive'. A positive PAK1-PKA/ ER $\alpha$ S305-P Score corresponds to a high likelihood of being tamoxifen resistant.

\section{Statistics}

Level of agreement between observers for pPKA staining was expressed by means of kappa. Clinicopathological characteristics according to pPKA were compared using Fisher's exact or Mann-Whitney U tests. Hazard ratios (HRs) were calculated using Cox regression analysis. Variables were entered into the multivariable model in one single step and including the clinicopathological variables used in previous studies for comparison [17, 18]. To evaluate whether tamoxifen benefit was modified by marker level, we allowed the tamoxifen-related $\mathrm{HR}$ to vary by marker level while adjusting for the main effect of the marker. Homogeneity of the tamoxifen-related HRs across marker levels was assessed by adding an interaction term between tamoxifen and marker level to a model including main effects for both factors. Analyses were performed using SPSS (version 15.0.1). 


\section{RESULTS}

In order to determine the clinical relevance of both PAK1, PPKA and phosphorylation of ERa at serine 305, we evaluated the expression of these three markers in a series of breast cancer patients $(n=103)$ who had received tamoxifen for metastatic disease (training series, clinical characteristics are presented in Table 1).

Tests for PAK1 and ERoS305-P have been described before [17, 18]. Active PKA was determined using an antibody detecting PKA phosphorylated at threonine 197 of the catalytic subunit (pPKA) [29]. To ensure that the antibody detects the phosphorylated form of PKA in FFPE tissues, sections were dephosphorylated prior to IHC. After treatment with lambda-phosphatase, no pPKA signal was detected (Supplementary Data Figure A1). Scoring of the intensity of pPKA staining by two observers resulted in a kappa of 0.84 $(p<0.0001)$. Clinico-pathological parameters according to PPKA are shown in the Supplementary Data (Table A2), and in Figure 1, which showed the proportion of tumors that express PAK1, pPKA or both. In addition, the coexpression of PAK1 and PKA with ERoS305-P was summarized.

Previously, we have shown that ERoS305-P status alters tamoxifen response in the adjuvant setting [18]. The association between ERoS305-P status and outcome after tamoxifen in the metastatic disease setting was less pronounced (Figure 2A) [18]. pPKA positivity alone was not associated with TTP after tamoxifen treatment (Figure 2B). However, patients with a tumor that co-expressed PPKA and ERoS305-P had a significantly worse outcome after tamoxifen treatment (Figure $\mathbf{2 C}$, univariate $\mathrm{HR}=2.00, \mathrm{p}=0.017$ ). In 
addition, PAK1 was related to tumor progression after tamoxifen (Figure 2D, univariate HR 1.57, $\mathrm{p}=0.055$, which is in line with our previous results [17]. Although PAK1 has been linked to ERoS305-P in vitro [13], the tumors that coexpressed PAK1 and ERoS305-P did not show a significantly increased risk for tumor progression compared to tumors that expressed PAK1 alone (Figure 2E).

These data suggested that PKA activity is linked to ERoS305-P, since tumors expressing both pPKA and ERoS305-P have a poor outcome after tamoxifen, while activation of PAK1 seems to be related to reduced tamoxifen sensitivity independent of ERos305-P. To verify the connection between PPKA and ERoS305-P in a direct manner, we activated PKA in the breast tumor cell line MCF7 by forskolin (an activator of PKA via cAMP induction) treatment. The levels of ERoS305-P were increased upon PKA activation (Figure 3, lane 2). Over-expression of the catalytic subunit of PKA also induced ERoS305-P (Figure 3, lane 5). Over-expressed PAK1 (PAK1 T423E, a constitutive kinase-active construct), however, did not affect ERoS305-P levels in MCF7 cells (Figure 3, lane 3). These in vitro results confirmed the clinical data indicating that ERais phosphorylated by PKA and not by PAK-1.

To further test whether ERoS305-P is indeed associated with PKA in human breast tumors, we evaluated gene expression of 11 tumors known to have a phosphorylated $\mathrm{ER}_{\alpha}$ at serine 305 and 47 ERoS305-P-negative tumors. These 58 tumors were selected because for these both $\mathrm{IHC}$ and gene expression data were available. The ERoS305-P-positive tumors were not significantly different from the rest of the trainingset presented above with 
respect to the proportion of PAK1 and pPKA expression (data not shown). Of the 302 pathways tested, 19 were differentially expressed in ERoS305-Ppositive tumors (permutated $p<0.05$, Table 2). The enrichment for pathways $(5 / 19=26 \%)$ that include one or more PKA subunits was significant $(p=0.019)$, while none of the 12 PAK1-related pathways was involved.

The in vitro experiments, the gene expression analysis as well as the clinical data in the training series, indicated that ERoS305-P is associated with pPKA but not with PAK1, suggesting that PAK1 is associated with sensitivity to tamoxifen via a mechanism independent of ERoS305-P. Indeed, upon adjustment for PAK1, co-expression of pPKA and ERoS305-P (PKA/ERoS305P) was still significantly associated with TTP (multivariable HR $1.37,95 \% \mathrm{Cl}$ 1.05-1.79, $\mathrm{p}=0.022)$. In addition, we did not see a significant overlap in between the PAK1 positive and PKA/ERoS305-P positive tumors $(p=0.25$, Fisher's Exact test). In order to capture both resistance mechanisms for predicting tamoxifen sensitivity, we combined PAK1 with pPKA-associated ERoS305-P which classified 38\% (39/103) of the patients in the training series (Figure 4A and 4B) with an increased risk for progression after tamoxifen (Figure 2F). In particular, the number of patients was increased by the combination of the two independent predictive markers. Multivariable Cox regression analysis revealed that the PAK1-PKA/ ER $\alpha$ S305-P Score identified a group of breast cancer patients who have a poor outcome after tamoxifen treatment independent of traditional factors (Table $\mathbf{3 A}$ ).

Next, we validated the PAK1-PKA/ ER $\alpha$ S305-P Score in an independent series $(n=231)$, which was a subgroup of patients from an adjuvant tamoxifen 
trial for whom sufficient material was available in order to assess the markers. They were not significantly different from the remaining group of patients with an ERa-positive tumor (Supplementary Data Figure A2, Table A3). In addition, the benefit from tamoxifen in the subset of 231 cases was similar to the tamoxifen benefit in the entire trial (Supplementary Data Figure A3). The proportions of tumors expressing ERoS305-P, pPKA or PAK1 in the validation series were comparable to those found in the training series (Table 1 and Figure 1). $27 \%$ of the tumors in the validation series had either PAK1 expression and/or pPKA-associated ERoS305-P (Figure 4C). These patients had no significant benefit from adjuvant tamoxifen (Figure 5B, HR=0.88, 95\% CI 0.42-1.82). whereas patients who were negative according to the PAK1PKA/ ER $\alpha$ S305-P Score did benefit from tamoxifen (Figure 5A, HR=0.54, $95 \% \mathrm{Cl} 0.34-0.87)$.

This difference was statistically significant in a multivariable analysis (interaction, $p=0.037$, Table 3B). Notably, the PAK1-PKA/ ER $\alpha$ S305-P Score was not significantly associated with RFS in patients not treated with tamoxifen (Figure $5 \mathrm{C}, \mathrm{HR}=0.88,95 \% \mathrm{Cl} 0.49-1.56$ ) or in the tamoxifen treated subpopulation (Figure 5D, HR=1.41, 95\% Cl 0.74-2.70).. Table A4 presents the distribution of prognostic factors in the subgroup of patients who were negative according to the PAK1-PKA/ ER $\alpha$ S305-P Score. No statistical differences in prognostic factors were seen between the treated arm versus the control group. The patients who were positive for the PAK1-PKA/ ER $\alpha$ S305-P Score had a poorer survival after tamoxifen than the Score- 
negative group of patients (Figure 5D). This difference was, however, not statistically significant $(p=0.30, H R=1.41,95 \% \mathrm{Cl} 0.74-2.70)$.

\section{DISCUSSION}

Here, we developed a score for tamoxifen sensitivity in metastatic breast cancer patients based on a combination of PKA-induced phosphorylation of ERaat serine 305 and levels of PAK1 in the primary tumor of the patient. The score was validated in an independent series of patients who were randomized between tamoxifen and no systemic treatment and identified breast cancer patients who benefit less from tamoxifen and who could be offered alternative treatment options. Besides assessment of the modification of the drug target (ER $\alpha$ ), the PAK1-PKA/ ER $\alpha$ S305-P Score incorporates information on kinase activities that can potentially modify the drug target. The PAK1-PKA/ ER $\alpha$ S305-P Score has several advantages over the use of a single marker: Firstly, a combination of markers may capture several resistance mechanisms, which is relevant for a heterogeneous disease such as breast cancer. Secondly, involvement of a particular signaling pathway is more reliably assessed by multiple measurements within that pathway, in particular in archived material using semi-quantitative assays. Our data validate this concept.

Although tamoxifen has reduced breast cancer mortality by $30 \%$, half of the treated patients at risk still develop a relapse despite adjuvant tamoxifen treatment [30]. It has been cumbersome to identify the endocrine agent most effective for an individual patient at high risk for recurrent disease. At present, the only validated predictive biomarker for tamoxifen response used in the 
clinic is ERaexpression, but this test has suboptimal positive predictive value. Data on the predictive value of PR are conflicting [22, 31, 32].

We confirmed the findings of Holm et al. that PAK1 levels are correlated with tamoxifen sensitivity [17]. Our study indicated no direct link between PAK1 and ERoS305-P, since outcome of the PAK1-positive group was not significantly affected by implementing ERoS305-P for the identification of tumors with poor outcome (see Figure 2E). In addition, our expression analysis showed no clear link between ERoS305P and PAK1-related pathways (see Table 2). Finally, in vitro PAK1 over-expression did not induce ERoS305P (see Figure 3). Although our data indicated that PAK1 is not directly involved in phosphorylation of ERoS305, PAK1 remained still an important additional marker in the identification of tamoxifen non -responders.

Our gene expression analysis revealed that pathways including PKA activity are overrepresented in tumors with an ERaphosphorylated at serine 305. This mechanism of PKA activation was first described by Miller et al., who showed a correlation between tamoxifen resistance and mRNA downregulation of a negative regulator of PKA (PKA-Rlo) [33], and was also supported by our previous work in which we correlated mRNA levels of PKA-Rla to outcome after adjuvant tamoxifen treatment in breast cancer patients. More importantly, we showed that PKA activity induced a modification of ERawhich in turn is causal for tamoxifen resistance in vitro [11]. Although phosphorylation of ERoS305 by PKA is clearly associated with tamoxifen resistance in vitro, pPKA expression alone appeared not to be sufficient to predict tamoxifen response (Figure 2B). The majority of breast tumors 
expressed pPKA, while approximately $20 \%$ of the tumors showed ERoS305-P. This suggests that additional factors like phosphatases, may play a role in causing detectable ERoS305-P. The weak association between the markers may also be due to the application of antibodies detecting phospho-proteins in archived samples. This may, in some cases, be complicated by fixation procedures that might affect the stability of phospho-proteins. On the other hand, the PAK1-PKA/ ER $\alpha$ S305-P Score was validated in an independent dataset from another hospital with stainings performed in a different laboratory. This indicated that, though the designs and patient selections were quite different between the training and validation series, the association of the PAK1-PKA/ ER $\alpha$ S305-P Score with RFS after tamoxifen treatment was roughly similar in both patient series, although it was somewhat weaker and no longer significant in the validation study. The differences between the training set and validation set regarding design and patient selection may limit the interpretation of our results. Lack of a placebo group in the training set did not allow a data-driven definition of a marker combination so that we therefore relied mainly on a biological-driven definition based on functional experiments. However, the main effect of the PAK1-PKA/ ER $\alpha$ S305-P Score in the validation set can be calculated from Table 3B as $\left(.71^{\star} 1.22\right) /\left(1.0^{*} .44\right)=1.97$, and is very similar to the 1.91 in Table $3 \mathbf{A}$ (training set).

Further research is needed to determine the diagnostic accuracy of the PAK1PKA/ ER $\alpha$ S305-P Score, such as sensitivity and specificity. Since patients in the validation series received only two years of tamoxifen treatment, further validation of the PAK1-PKA/ ER $\alpha$ S305-P Score has to be done for the 
currently prescribed five years of adjuvant endocrine treatment. In addition, our data are based on a subgroup of patient that had predominantly lymphnode positive disease, resulting in a relatively poor survival even in the subgroup predicted as 'tamoxifen sensitive' by our Predictive Score. Consequently, our study design allows the selection of patients who may have sufficient benefit of tamoxifen monotherapy in the adjuvant setting. Finally, the PAK1-PKA/ ER $\alpha$ S305-P Score identified between 54 and $76 \%$ of the resistant cases in the respective breast cancer series. The remainder fraction has yet to be identified, but is still present in the tamoxifen-responsive subgroup of patients (Figures 2F and 5D). The PAK1-PKA/ ER $\alpha$ S305-P Score identifies therefore, a subfraction of the patients who benefit less from tamoxifen treatment.

Each of the markers, PAK1 and pPKA/ERoS305P, identified a separate group of patients in both series of breast cancer patients that showed a reduced response to tamoxifen. The combination of these markers, however, enabled us to identify a major proportion of the less tamoxifen responsive cases. The combined marker identified $38 \%$ and $27 \%$ of the total number of breast cancer patients in the test and validation series, respectively, as tamoxifen resistant. In each set of patients, approximately half of the patients are expected to become resistant to tamoxifen. This implies that the combined marker identified respectably $76 \%$ and $54 \%$ of all tamoxifen resistant cases in these two breast cancer patient series.

In this study, we confirmed the correlation between PAK1 and tamoxifen resistance and provided evidence for the relationship between pPKA and 
ERoS305-P that is relevant for tamoxifen response in patients. The proportion of tumors that have both PAK1 as well as pPKA-associated ERoS305-P was limited (9\% in training, $0.4 \%$ in validation, Figure 4$)$ suggesting that the three markers reflect two different mechanisms. We have shown previously that the effects of tamoxifen on RFS in subgroups defined by PAK1 alone were different [17]. The current study provides evidence that pPKA/ERoS305-P is a marker for tamoxifen sensitivity that is not related to PAK1. Using both markers resulted in the identification of an increased proportion of patients (27\% based on the PAK1-PKA/ ER $\alpha$ S305-P Score versus $14 \%$ based on PAK1 alone) who are less sensitive to tamoxifen (Figure 4).

Only a few candidate biomarkers predicting drug response progress from laboratory to the clinic. Accurate patient stratification into responders and nonresponders on the basis of one single biomarker is rare. The strength of the predictive PAK1-PKA/ ER $\alpha$ S305-P Score presented here is not only that it combined three markers and consequently captures PKA/PAK1-pathway activities at different levels in the signaling cascade, but that the implication of all three markers in tamoxifen sensitivity is supported by extensive functional experiments $[11-15,17]$. This PAK1-PKA/ ER $\alpha$ S305-P Score may provide an important step towards personalized anti-estrogen therapy as patients who have less benefit from tamoxifen have alternative treatment options such as fulvestrant or aromatase inhibitors and thus may improve the outcome of breast cancer. 


\section{LEGENDS}

\section{Figure 1}

Expression of PAK1, pPKA and ER@S305-P in human breast tumors.

Proportion of tumors expressing nuclear PAK1, pPKA and/or ERoS305-P. Below, the co-expression of PAK1 and PPKA with ERoS305P is depicted.

\section{Figure 2}

Association of ERoS305-P, pPKA and PAK1 with outcome after tamoxifen treatment for metastatic disease (training series)

Kaplan-Meier analysis according to ERoS305-P, pPKA and nuclear PAK1 expression in 103 patients. All HR and p-values are based on univariate Cox regression analysis. A) Time to tumor progression (TTP) according to ERoS305-P, B) TTP according to pPKA, C) TTP according to ERoS305-P and pPKA. Red line represents patients with a tumor co-expressing ERaS305-P and $\mathrm{pPKA}$. Blue line represents patients with a tumor expressing PPKA but no ERoS305-P. HR and p-value estimate the difference between the groups depicted in blue and red, D) TTP according to nuclear PAK1, E) TTP according to ERoS305-P and nuclear PAK1. Red line represents patients with a tumor co-expressing ERoS305-P and PAK1. Blue line represents patients with a tumor expressing PAK1 but no ERoS305-P. HR and p-value estimate the difference between the groups depicted in blue and red. F) TTP according to the ERoS305-P/pPKA and PAK1. Red line represents patients with a tumor expressing pPKA-associated ERoS305-P, and/or nuclear PAK1. Green line 
represents patients with a tumor that is expressing neither nuclear PAK1 nor pPKA-associated ERoS305-P.

\section{Figure 3}

\section{PAK1 does not directly phosphorylate ER $\alpha$ S305 in MCF-7 cells}

Western blot analysis of MCF-7 breast cancer cells expressing kinase-active PAK1-T423E (lanes $3,4,7,8$ ) either or not in combination with the catalytic subunit of PKA, PKA-cat, (lanes 5-8). In the even lanes, cells were treated for 30 minutes prior to lysis with $10_{\mu} \mathrm{M}$ forskolin for PKA activation, whereas cells were untreated in uneven lanes. Protein was analyzed for expression of ER $\alpha$, ER $\alpha$ S305-P, PAK1, PKA and $\alpha$-tubulin (loading control). While both PKA activation and PKA-cat overexpression induced phosphorylation of ER $\alpha \mathrm{S} 305$ $\mathrm{P}$, this did not occur when overexpressing PAK1.

\section{Figure 4}

The PAK1-PKA/ ER $\alpha$ S305-P Score affects outcome of tamoxifen treatment
A) Categories defined by the PAK1-PKA/ ER $\alpha$ S305-P Score. B) and C) Illustration of the predictive PAK1-PKA/ ER $\alpha$ S305-P Score and the proportion of patients classified as less sensitive to tamoxifen. 


\section{Figure 5}

Association of the PAK1-PKA/ ER $\alpha$ S305-P Score with outcome after adjuvant tamoxifen treatment (validation series)

Kaplan-Meier analysis according to the PAK1-PKA/ ER $\alpha$ S305-P Score in 231 patients. Recurrence-free survival (RFS) of patients who had been randomly assigned to tamoxifen or no adjuvant systemic treatment. Tumors with no PAK1 and no pPKA-associated ER $\alpha$ S305-P expression (A), and tumors with either PAK1 and/or pPKA-associated ER $\alpha$ S305-P expression (B) were analyzed separately. (C) RFS according to the PAK1-PKA/ER $\alpha$ S305-P Score among patients who did not receive any adjuvant treatment (controls). (D) RFS according to the PAK1-PKA/ ER $\alpha$ S305-P Score among patients who did receive adjuvant tamoxifen. 


\section{ACKNOWLEDGEMENTS}

The authors would like to thank Desiree Verwoerd for technical assistance Guus Hart for statistical advice and Marieke Vollebergh, Stella Mook, Els Berns and Stefan Sleijfer for critical reading. We thank dr Jonathan Chernoff and dr M Zaccolo for the generous gift of the expression constructs. This research was supported by Dutch Cancer Society, TI Pharma, A Sister's Hope, Swedish Cancer Society, Malmö University Hospital Research and Cancer Funds and Astra Zeneca. 
1. Pritchard KI (2003) Endocrine therapy of advanced disease: analysis and implications of the existing data. Clin Cancer Res 9:460S-467S

2. O'Regan RM, Jordan VC (2002) The evolution of tamoxifen therapy in breast cancer: selective oestrogen-receptor modulators and downregulators. Lancet Oncol 3:207-214

3. Johnston SR, Dowsett M (2003) Aromatase inhibitors for breast cancer: lessons from the laboratory. Nat Rev Cancer 3:821-831

4. Wakeling AE, Dukes M, Bowler J (1991) A potent specific pure antiestrogen with clinical potential. Cancer Res 51:3867-3873

5. Osborne CK, Pippen J, Jones SE, Parker LM, Ellis M, Come S, Gertler SZ, May JT, Burton G, Dimery I, Webster A, Morris C, Elledge R, Buzdar A (2002) Double-blind, randomized trial comparing the efficacy and tolerability of fulvestrant versus anastrozole in postmenopausal women with advanced breast cancer progressing on prior endocrine therapy: results of a North American trial. J Clin Oncol 20:3386-3395

6. Howell A, Robertson JF, Quaresma Albano J, Aschermannova A, Mauriac L, Kleeberg UR, Vergote I, Erikstein B, Webster A, Morris C (2002) Fulvestrant, formerly ICI 182,780 , is as effective as anastrozole in 
postmenopausal women with advanced breast cancer progressing after prior endocrine treatment. J Clin Oncol 20:3396-3403

7. Miller WR, Bartlett JM, Canney P, Verrill M (2007) Hormonal therapy for postmenopausal breast cancer: the science of sequencing. Breast Cancer Res Treat 103:149-160

8. Rabaglio M, Aebi S, Castiglione-Gertsch M (2007) Controversies of adjuvant endocrine treatment for breast cancer and recommendations of the 2007 St Gallen conference. Lancet Oncol 8:940-949

9. Jordan VC, O'Malley BW (2007) Selective estrogen-receptor modulators and antihormanal resistance in breast cancer. J Clin Oncol 25:5815-5824

10. Ali S, Coombes RC (2002) Endocrine-responsive breast cancer and strategies for combating resistance. Nat Rev Cancer 2:101-112

11. Michalides R, Griekspoor A, Balkenende A, Verwoerd D, Janssen L, Jalink K, Floore A, Velds A, van't Veer L, Neefjes J (2004) Tamoxifen resistance by a conformational arrest of the estrogen receptor alpha after PKA activation in breast cancer. Cancer Cell 5:597-605

12. Zwart W, Griekspoor A, Berno V, Lakeman K, Jalink K, Mancini M, Neefjes J, Michalides R (2007) PKA-induced resistance to tamoxifen is associated with an altered orientation of ERalpha towards co-activator SRC-1. EMBO J 26:3534-3544 
13. Wang RA, Mazumdar A, Vadlamudi RK, Kumar R (2002) P21-activated kinase-1 phosphorylates and transactivates estrogen receptor-alpha and promotes hyperplasia in mammary epithelium. EMBO J 21:5437-5447

14. Rayala SK, Talukder AH, Balasenthil S, Tharakan R, Barnes CJ, Wang RA, Aldaz M, Khan S, Kumar R (2006) P21-activated kinase 1 regulation of estrogen receptor-alpha activation involves serine 305 activation linked with serine 118 phosphorylation. Cancer Res 66:1694-1701

15. Balasenthil S, Barnes CJ, Rayala SK, Kumar R (2004) Estrogen receptor activation at serine 305 is sufficient to upregulate cyclin D1 in breast cancer cells. FEBS Lett 567:243-247

16. Bostner J, Ahnstrom Waltersson M, Fornander T, Skoog L, Nordenskjold B, Stal O (2007) Amplification of CCND1 and PAK1 as predictors of recurrence and tamoxifen resistance in postmenopausal breast cancer. Oncogene 26:6997-7005

17. Holm C, Rayala S, Jirstrom K, Stal O, Kumar R, Landberg G (2006) Association between Pak1 expression and subcellular localization and tamoxifen resistance in breast cancer patients. J Natl Cancer Inst $98: 671-680$

18. Holm C, Kok M, Michalides R, Fles R, Koornstra RH, Wesseling J, Hauptmann M, Neefjes J, Peterse JL, Stal O, Landberg G, Linn SC (2009) Phosphorylation of the oestrogen receptor alpha at serine 305 
and prediction of tamoxifen resistance in breast cancer. J Pathol 217:372-379

19. McShane LM, Altman DG, Sauerbrei W, Taube SE, Gion M, Clark GM (2005) Reporting recommendations for tumor marker prognostic studies (REMARK). J Natl Cancer Inst 97:1180-1184

20. Kok M, Linn SC, Van Laar RK, Jansen MP, van den Berg TM, Delahaye LJ, Glas AM, Peterse JL, Hauptmann M, Foekens JA, Klijn JG, Wessels LF, Van't Veer LJ, Berns EM (2009) Comparison of gene expression profiles predicting progression in breast cancer patients treated with tamoxifen. Breast Cancer Res Treat 113:275-283

21. Ryden L, Jirstrom K, Bendahl PO, Ferno M, Nordenskjold B, Stal O, Thorstenson S, Jonsson PE, Landberg G (2005) Tumor-specific expression of vascular endothelial growth factor receptor 2 but not vascular endothelial growth factor or human epidermal growth factor receptor 2 is associated with impaired response to adjuvant tamoxifen in premenopausal breast cancer. J Clin Oncol 23:4695-4704

22. Ryden L, Jonsson PE, Chebil G, Dufmats M, Ferno M, Jirstrom K, Kallstrom AC, Landberg G, Stal O, Thorstenson S, Nordenskjold B (2005) Two years of adjuvant tamoxifen in premenopausal patients with breast cancer: a randomised, controlled trial with long-term follow-up. Eur J Cancer 41:256-264 
23. Liu CL, Montgomery KD, Natkunam Y, West RB, Nielsen TO, Cheang MC, Turbin DA, Marinelli RJ, van de Rijn M, Higgins JP (2005) TMACombiner, a simple software tool to permit analysis of replicate cores on tissue microarrays. Mod Pathol 18:1641-1648

24. Beeser A, Jaffer ZM, Hofmann C, Chernoff J (2005) Role of group A p21activated kinases in activation of extracellular-regulated kinase by growth factors. J Biol Chem 280:36609-36615

25. Zaccolo M, De Giorgi F, Cho CY, Feng L, Knapp T, Negulescu PA, Taylor SS, Tsien RY, Pozzan T (2000) A genetically encoded, fluorescent indicator for cyclic AMP in living cells. Nat Cell Biol 2:25-29

26. Xu X, Zhao Y, Simon R (2008) Gene set expression comparison kit for BRB Array Tools. Bioinformatics 24: 137-139

27. BRB Array Tools Manual (Version 3.8), p. 70. http://linus.nci.nih.gov/ brb/download_individual_new.html

28. Fisher R.A (1922) On the interpretation of $X^{2}$ from contingency tables, and the calculation of P. Journal of the Royal Statistical Society 85: 8794

29. Moore MJ, Kanter JR, Jones KC, Taylor SS (2002) Phosphorylation of the catalytic subunit of protein kinase A. Autophosphorylation versus 
phosphorylation by phosphoinositide-dependent kinase-1. J Biol Chem $277: 47878-47884$

30. Early Breast Cancer Trialists' Collaborative Group (2005) Effects of chemotherapy and hormonal therapy for early breast cancer on recurrence and 15-year survival: an overview of the randomised trials. Lancet 365:1687-1717

31. Bezwoda WR, Esser JD, Dansey R, Kessel I, Lange M (1991) The value of estrogen and progesterone receptor determinations in advanced breast cancer. Estrogen receptor level but not progesterone receptor level correlates with response to tamoxifen. Cancer 68:867-872

32. Viale G, Regan MM, Maiorano E, Mastropasqua MG, Dell'Orto P, Rasmussen BB, Raffoul J, Neven P, Orosz Z, Braye S, Ohlschlegel C, Thurlimann B, Gelber RD, Castiglione-Gertsch M, Price KN, Goldhirsch A, Gusterson BA, Coates AS (2007) Prognostic and predictive value of centrally reviewed expression of estrogen and progesterone receptors in a randomized trial comparing letrozole and tamoxifen adjuvant therapy for postmenopausal early breast cancer: BIG 1-98. J Clin Oncol 25:38463852

33. Miller WR, Hulme MJ, Bartlett JM, MacCallum J, Dixon JM (1997) Changes in messenger RNA expression of protein kinase A regulatory subunit ialpha in breast cancer patients treated with tamoxifen. Clin Cancer Res 3:2399-2404 
Table 1. Patient characteristics

\begin{tabular}{|c|c|c|c|c|c|}
\hline & & \multicolumn{2}{|c|}{ Training ( $n=103$ ) } & \multicolumn{2}{|c|}{ Validation $(\mathrm{n}=\mathbf{2 3 1})$} \\
\hline Variable & Category & $\mathbf{N}$ & $\%$ & $\mathbf{N}$ & $\%$ \\
\hline Year of diagnosis & Range & 1977-1997 & & $1986-1991$ & \\
\hline Time to tumor progression* & Median in months (range) & $14(1-169)$ & & & \\
\hline Follow-Up & Median in years (range) & & & $12(0-17)$ & \\
\hline Age at surgery & Median in years (range) & $60(36-83)$ & & $45(26-57)$ & \\
\hline Grade $^{\star *}$ & $\begin{array}{l}\text { I/II } \\
\text { III } \\
\text { Unknown }\end{array}$ & $\begin{array}{l}71 \\
32\end{array}$ & $\begin{array}{l}69 \% \\
31 \%\end{array}$ & $\begin{array}{r}151 \\
77 \\
3\end{array}$ & $\begin{array}{l}66 \% \\
34 \%\end{array}$ \\
\hline Lymph Node Status & $\begin{array}{l}\text { Negative } \\
\text { Positive } \\
\text { Unknown }\end{array}$ & $\begin{array}{r}68 \\
33 \\
2\end{array}$ & $\begin{array}{l}67 \% \\
33 \%\end{array}$ & $\begin{array}{r}55 \\
176\end{array}$ & $\begin{array}{l}24 \% \\
76 \%\end{array}$ \\
\hline WHO subtype & $\begin{array}{l}\text { Invasive Ductal Carcinoma } \\
\text { Invasive Lobular Carcinoma } \\
\text { Unknown or other subtype }\end{array}$ & $\begin{array}{r}87 \\
12 \\
4\end{array}$ & $\begin{array}{l}88 \% \\
12 \%\end{array}$ & $\begin{array}{r}196 \\
23 \\
12\end{array}$ & $\begin{array}{l}89 \% \\
11 \%\end{array}$ \\
\hline Size & $\begin{array}{l}\leq 20 \mathrm{~mm} \\
>20 \mathrm{~mm}\end{array}$ & $\begin{array}{l}61 \\
42\end{array}$ & $\begin{array}{l}59 \% \\
41 \%\end{array}$ & $\begin{array}{r}97 \\
134\end{array}$ & $\begin{array}{l}42 \% \\
58 \%\end{array}$ \\
\hline Progesterone Receptor (IHC) & $\begin{array}{l}\leq 10 \% \\
>10 \% \\
\text { Unknown }\end{array}$ & $\begin{array}{l}36 \\
67\end{array}$ & $\begin{array}{l}35 \% \\
65 \%\end{array}$ & $\begin{array}{r}22 \\
196 \\
13\end{array}$ & $\begin{array}{l}10 \% \\
96 \%\end{array}$ \\
\hline ERaS305-P (IHC) & $\begin{array}{l}\text { Negative } \\
\text { Positive } \\
\text { Unknown }\end{array}$ & $\begin{array}{l}83 \\
20\end{array}$ & $\begin{array}{l}81 \% \\
19 \%\end{array}$ & $\begin{array}{r}178 \\
35 \\
18\end{array}$ & $\begin{array}{l}84 \% \\
16 \%\end{array}$ \\
\hline pPKA (IHC) & $\begin{array}{l}\text { Negative } \\
\text { Positive } \\
\text { Unknown }\end{array}$ & $\begin{array}{l}30 \\
73\end{array}$ & $\begin{array}{l}29 \% \\
71 \%\end{array}$ & $\begin{array}{r}25 \\
165 \\
41\end{array}$ & $\begin{array}{l}13 \% \\
87 \%\end{array}$ \\
\hline PAK1 (IHC) & $\begin{array}{l}\text { Negative } \\
\text { Positive } \\
\text { Unknown }\end{array}$ & $\begin{array}{l}75 \\
28\end{array}$ & $\begin{array}{l}73 \% \\
27 \%\end{array}$ & $\begin{array}{r}191 \\
34 \\
6\end{array}$ & $\begin{array}{l}85 \% \\
15 \%\end{array}$ \\
\hline
\end{tabular}

* Measured from start until stop tamoxifen treatment.

** According Nottingham Grading system (Elston et al. Histopathology 1993).

$\mathrm{IHC}=$ immunohistochemistry, ERaS305-P= phosphorylation of ER at serine $305, \mathrm{pPKA}=$ phosphorylated PKA, PAK1= p21-activated kinase 
Table 2. Pathways which have genes differentially expressed in ERaS305-P positive tumors Inhibition of Matrix Metalloproteinases PRKACA

\begin{tabular}{|c|c|c|c|}
\hline 6 & Role of MAL in Rho-mediated activation of SRF & & 0.014 \\
\hline 7 & IFN alpha signaling pathway & & 0.022 \\
\hline 8 & mCalpain and friends in Cell motility & PRKAR1B & 0.023 \\
\hline 9 & $\mathrm{BCR}$ signaling pathway & & 0.023 \\
\hline 10 & Steps in the glycosylation of mammalian $\mathrm{N}$-linked oligosaccarides & & 0.025 \\
\hline 11 & Actions of Nitric Oxide in the Heart & PRKAR1B & 0.031 \\
\hline 12 & EGF signaling & & 0.035 \\
\hline 13 & Generation of amyloid b-peptide by PS1 & & 0.036 \\
\hline 14 & HIV Induced T cell apoptosis & & 0.038 \\
\hline 15 & Hypoxia and p53 in the cardiovascular system & & 0.042 \\
\hline 16 & Phosphorylation of MEK 1 by cdk5/p35 downregulates the MAP kinase pathway & & 0.042 \\
\hline 17 & CDK regulation of DNA replication & & 0.044 \\
\hline 18 & $\begin{array}{l}\text { Nuclear receptors coordinate the activities of chromatin remodeling complexes and coactivators to facilitate initiation of transcription in carcinoma } \\
\text { cells }\end{array}$ & & 0.046 \\
\hline 19 & Bone remodelling & & 0.046 \\
\hline
\end{tabular}

ERaS305-P positive tumours $(n=11)$ were compared with ERaS305-P negative tumours ( $n=47)$ using gene expression profiling.

42,034 genes were used for the analysis. 302 pathways as defined by Biocarta were tested using the Gene Set Comparison Tool in BRB array tools. The pathways that had a permuted $p$-value $<0.05$ are included in the table. In the 302 pathways tested, 27 are known to be related to PKA (Cancer Genome Anatomy Project). The expression of 5 out of the 27 pathways turned out to be significantly associated with ERaS305-P status.

Enrichment, within the significant pathways, for PKA-related pathways was tested using Fisher's Exact test: odds ratio $=4.24, p=0.019$

* Based on 100,000 permutations. The Fishers's LS (least squares) summary statistic uses the average log P values for the genes in that class. 
Table 3. Multivariable Cox regression analysis of the risk of progression after tamoxifen according to the PAK1-PKA/ ERc\$305-P Score

A.Trainingset, NKI, tamoxifen for metastatic disease

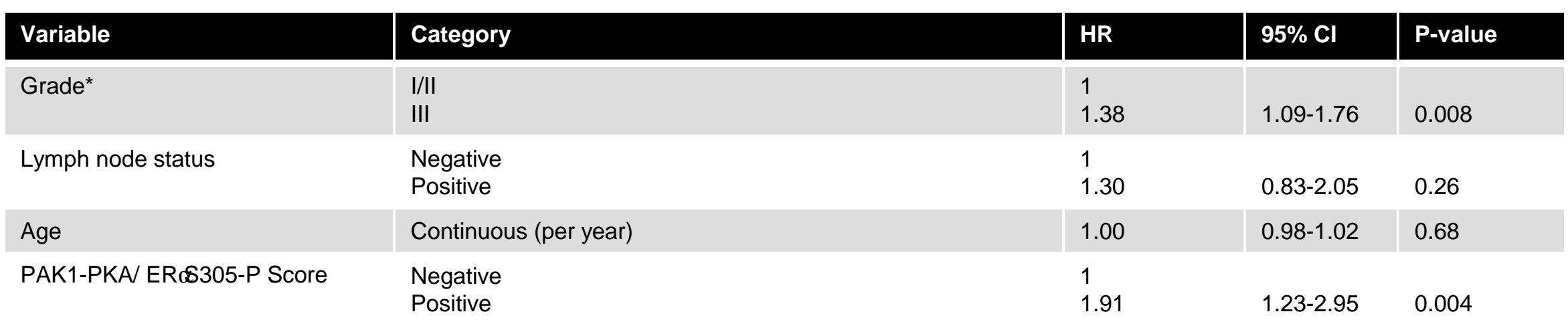

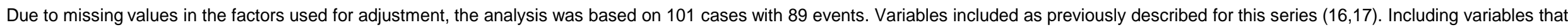
performed significant in this trainingset in univariate analyses (progesterone receptor, HER2 and disease-free interval) did not substantially change the HR for the Algorithm.

Ki67 was not available for this series. * Nottingham grading system

B. Validationset, Lund, adjuvant tamoxifen versus no systemic treatment in randomized trial

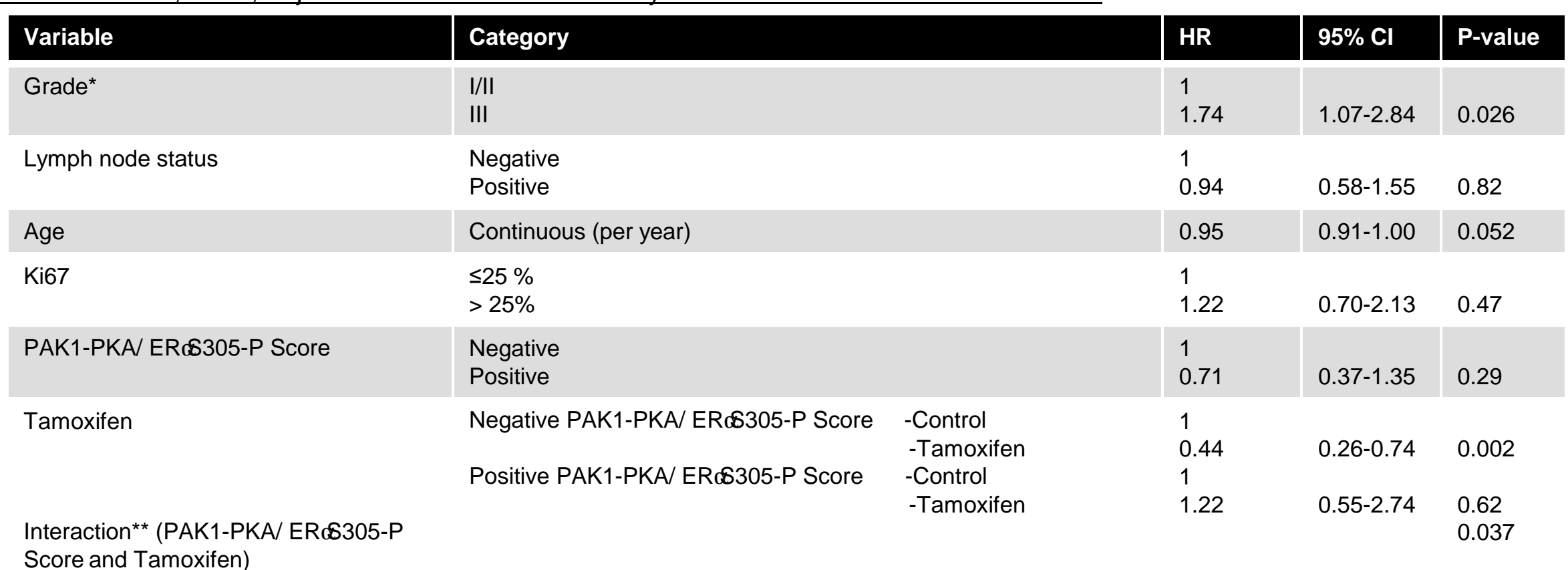

Due to missing values in the factors used for adjustment, the analysis was based on 201 cases with 88 events. Variables included as previously described for this series (16,17)

${ }^{*}$ Nottingham grading system

** The interaction variable indicates whether there is a difference in treatment response in relation to the PAK1-PKA/ ER $₫ 305-P$ Score. 
Figure 1. Expression of PAK1, pPKA and ERaS305-P in human breast tumors

A. Training series $(n=103)$

B. Validation set $(n=231)$

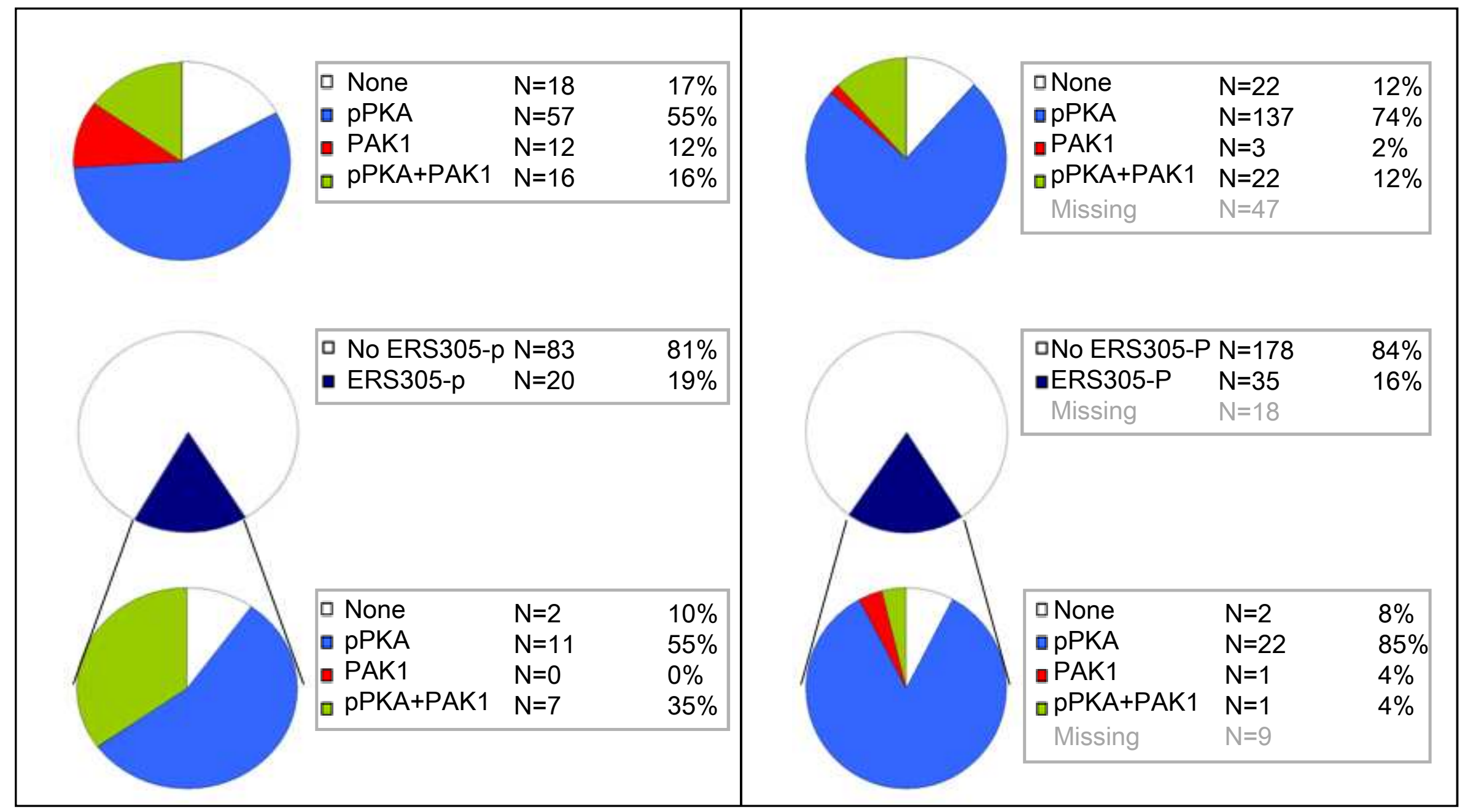




\section{A. ERaS305-P}

\section{- No ERaS305-P}

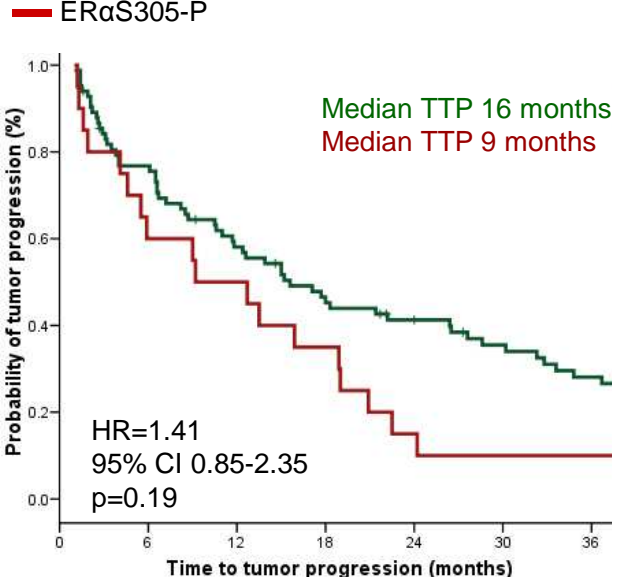

No. at risk

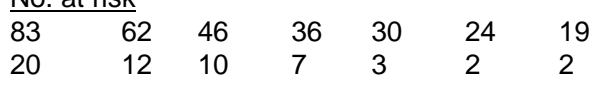

D. PAK1

\section{No PAK1}

PAK

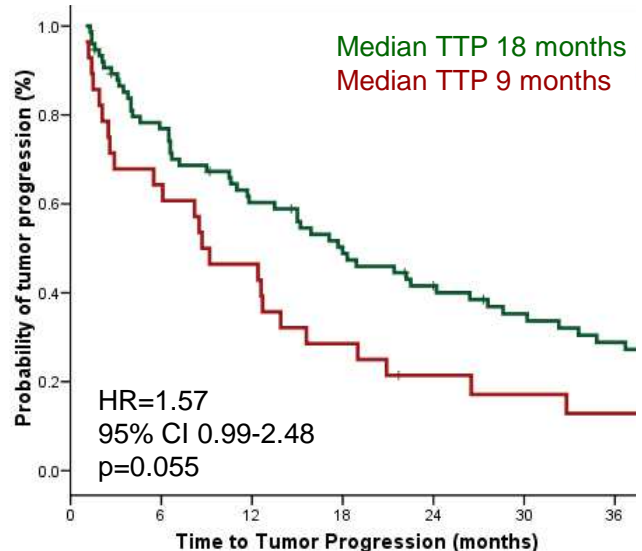
Time to Tumor Progression (months)

\begin{tabular}{lllllll}
\multicolumn{2}{l}{ No. at risk } \\
\hline 75 & 56 & 43 & 35 & 28 & 22 & 18 \\
28 & 18 & 13 & 8 & 5 & 4 & 3
\end{tabular}

$$
\text { B. PPKA }
$$

- No pPKA

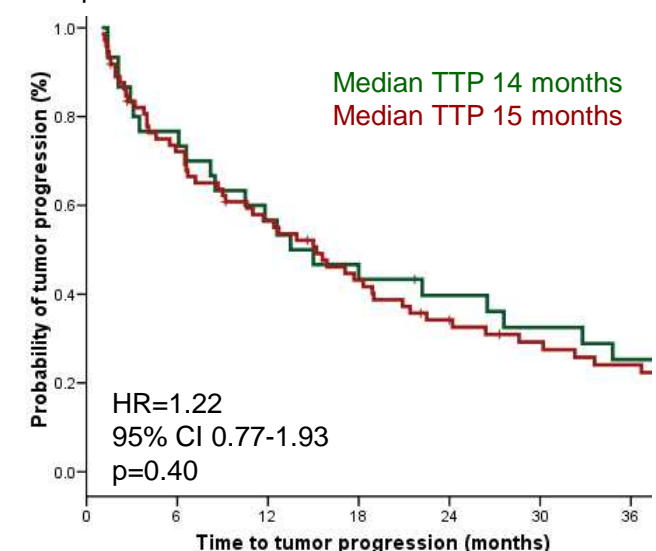

No. at risk

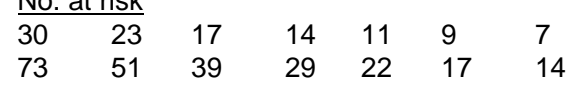

\section{E. ERaS305-P and PAK1}

\section{- No PAK}

- PAK1

- PAK1-associated ERaS305-P

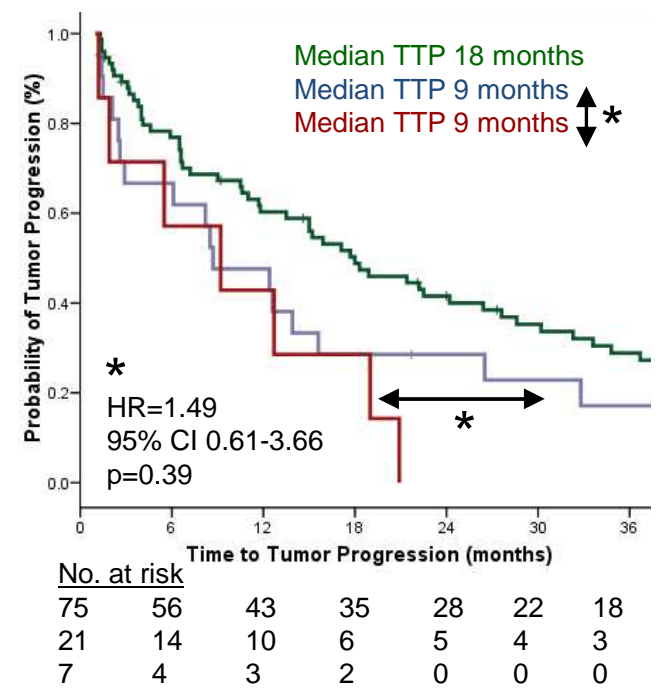

C. ERaS305-P and pPKA Figure 2

No pPKA

- pPKA-associated ERaS305-P

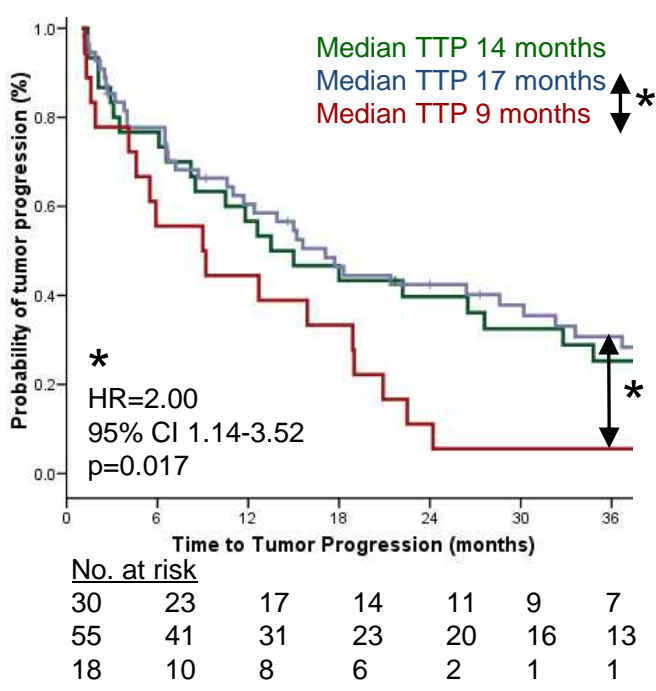

\section{F. ERaS305-P, pPKA and PAK1}

- No pPKA-associated ERaS305-P and no PAK1

- pPKA-associated ERaS305-P and/or PAK1

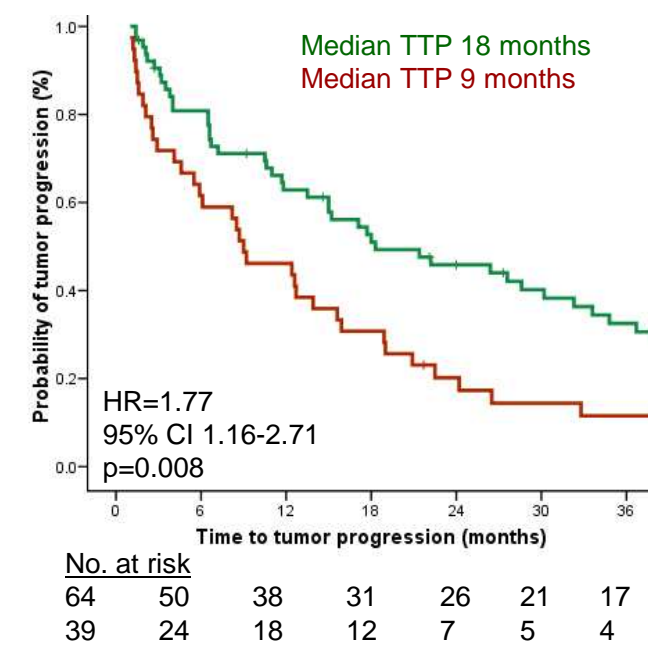




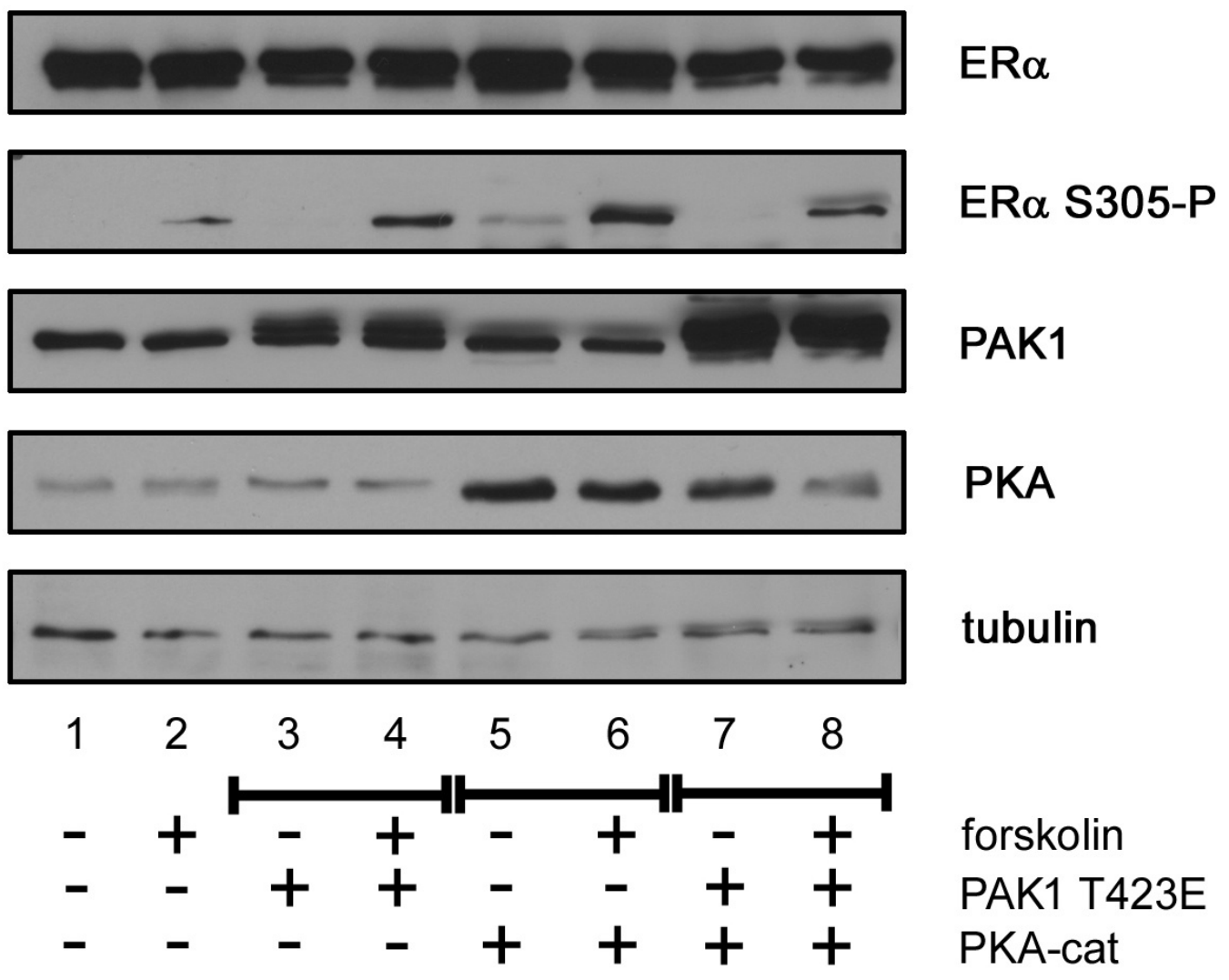


- PAK1 OR pPKA-associated ERS305-P positive = PAK1-PKA/ ER(6305-P Score positive $=$ tumor classified as less sensitive - IF (No PAK1) AND (No pPKA-associated ERS305-P) = PAK1-PKA/ ERc6305-P Score negative = tumor classified as sensitive

B. Training series $(n=103)$

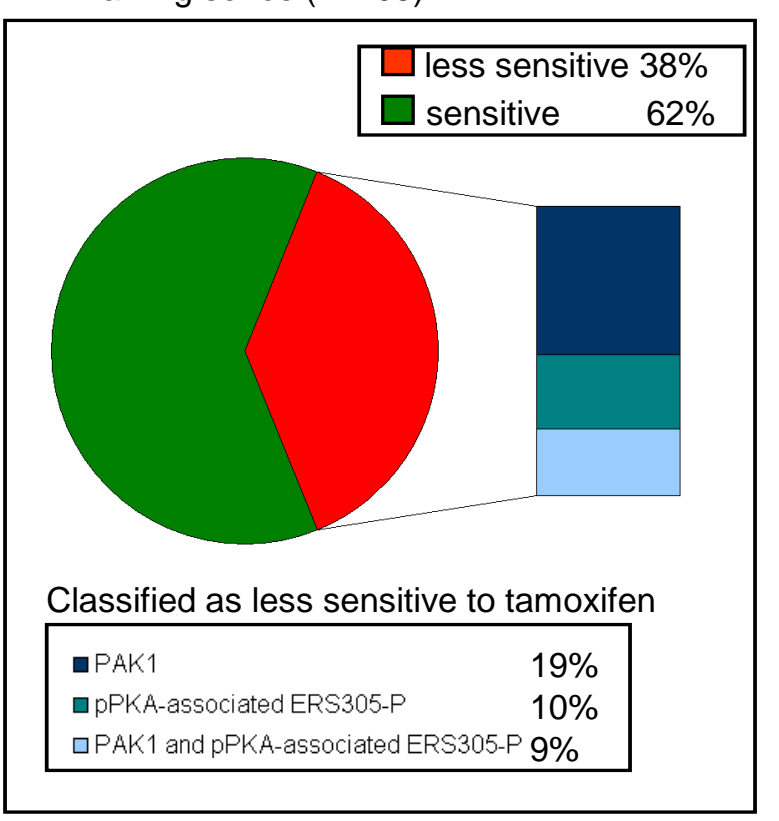

C. Validation set $(n=231)$

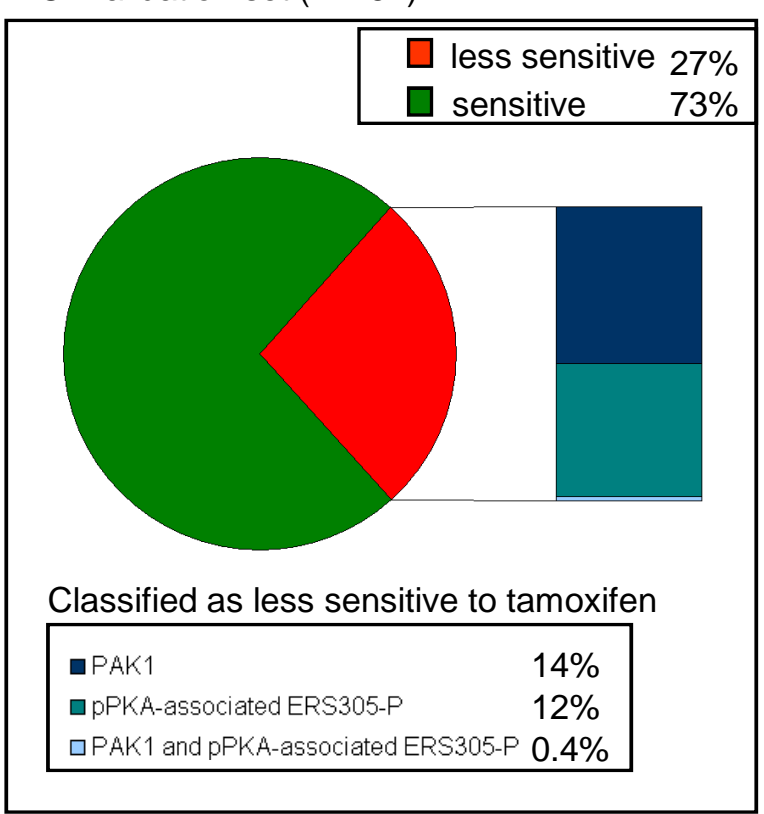


A. No pPKA-associated ERaS305-P and no PAK1 (PAK1-PKA/ ERø6305-P Score negative)

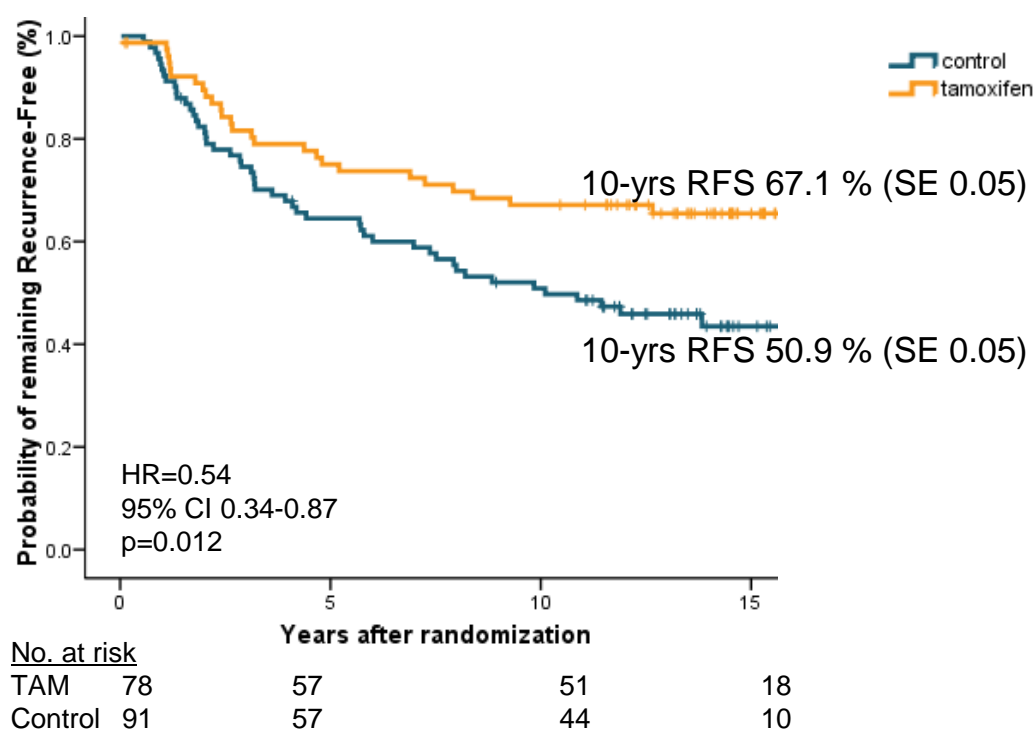

C. Untreated patients

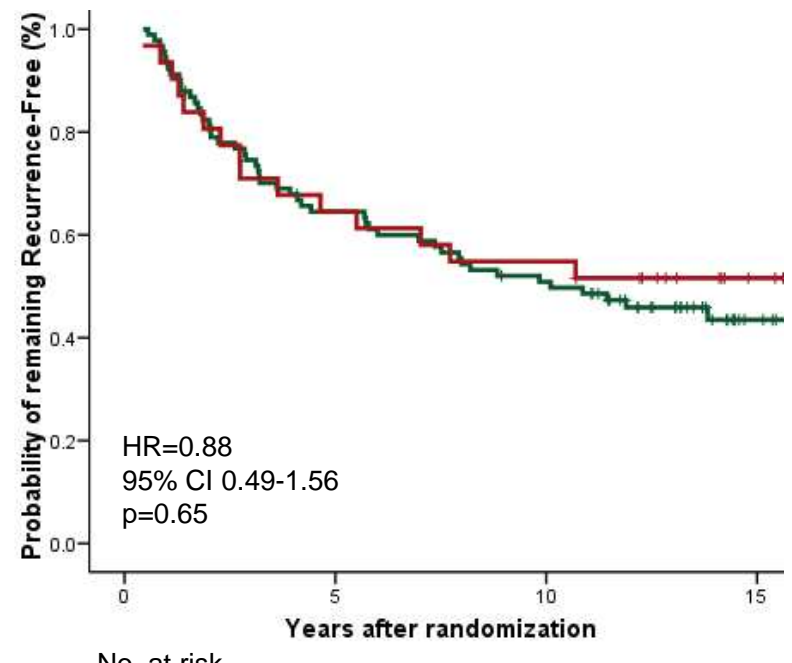

No. at risk

PAK1-PKA/ ER66305-P Score positive

$\begin{array}{llll}31 & 20 & 17 & 6\end{array}$

PAK1-PKA/ ER66305-P Score negative

91

57
B. pPKA-associated ERaS305-P and/or PAK1

Figure5 (PAK1-PKA/ ERo6305-P Score positive)

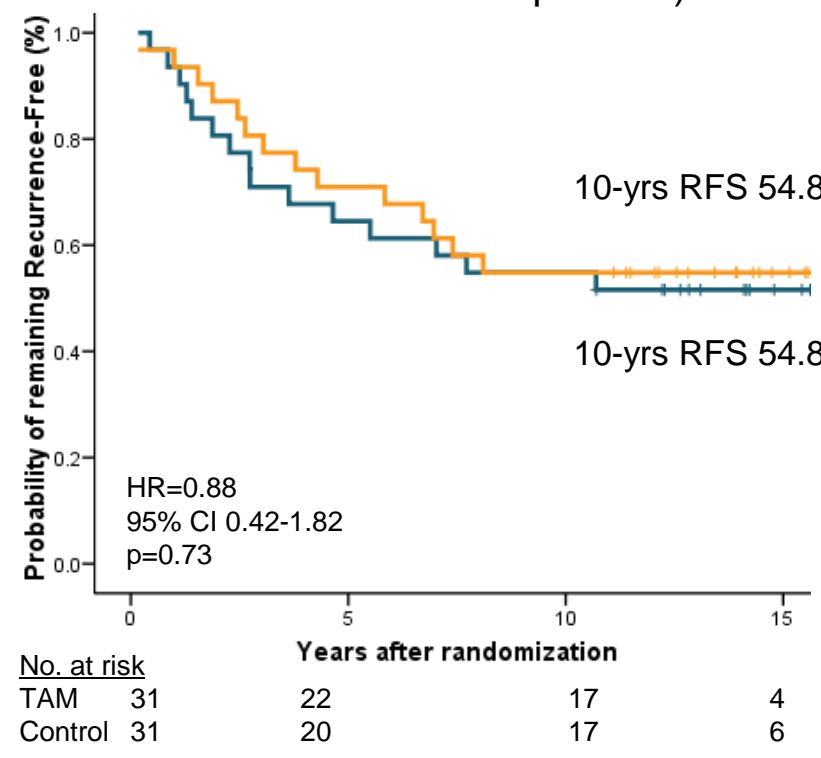

D. Tamoxifen treated patients

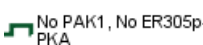
$\Omega_{\mathrm{PKA}}^{\mathrm{PAK} 1 \text { and/or ER } 305 \mathrm{P} \text { - }}$

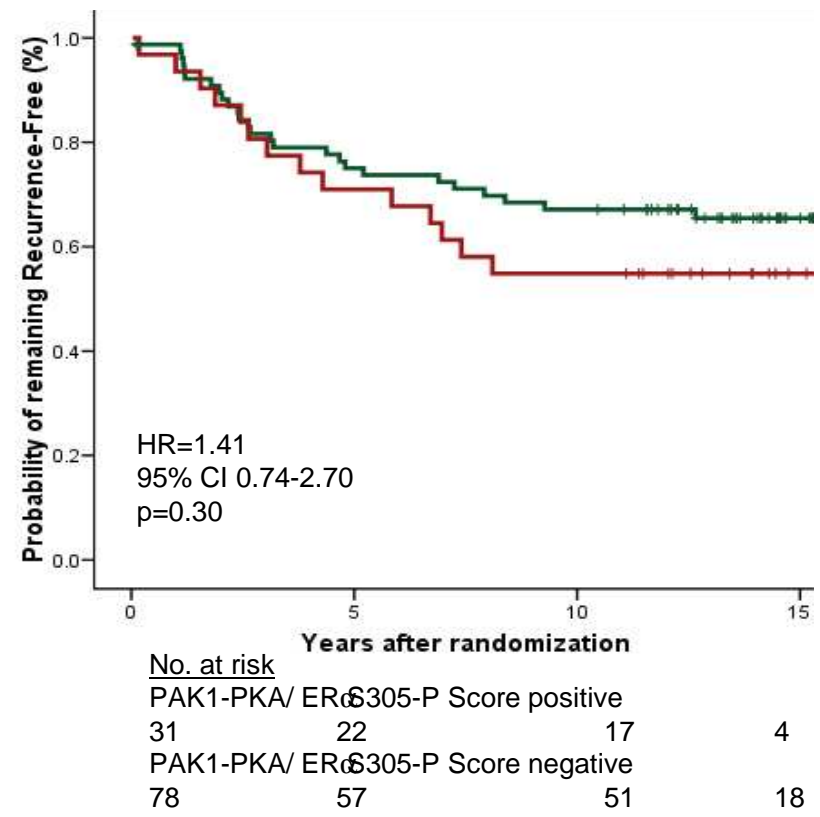

$\boldsymbol{\Omega}_{\mathrm{P} \text { POA }}^{\text {No PAK1, No ER305p- }}$ $\Omega_{\mathrm{PKA}}^{\mathrm{PAK} 1 \text { and/or ER305p- }}$ 